\title{
A method to study the two-step decomposition of binary blends in cone calorimeter
}

\author{
Rodolphe Sonnier*, Amandine Viretto, Loïc Dumazert, Benjamin Gallard \\ Centre des Matériaux de l'Ecole des Mines d'Alès - 6, Avenue de Clavières, 30319 Alès Cedex, France
}

\begin{abstract}
A B S T R A C T
A method to distinguish the mass loss rates corresponding to each of the two decomposition steps in binary blends is proposed. This method is suitable for cone calorimeter test and all other tests measuring continuously mass loss and heat release in an independent way. Heat release rate curves recalculated from the method well fit the experimental ones. Several systems including copolymers, polymers filled with inert or hydrated fillers and binary blends were studied. It appears that the decomposition of these materials is complex because the decomposition rate of one component influences the decomposition rate of the second one. These interactions depend on the materials, their content and also the external heat flux. Concerning binary blends, first results show the decomposition of the most thermally stable polymer is delayed because the temperature within the material is maintained close to the pyrolysis temperature of the least thermally stable polymer. Longer is the delay, higher is the decomposition rate of the most thermally stable polymer. In some cases, this polymer can decompose at higher rate (but later) than the least stable polymer.
\end{abstract}

Keywords:

Cone calorimeter

Binary blends

Fire behavior

\section{Introduction}

The behavior of a material during burning is rather complex because it involves many chemical and physical phenomena. Moreover, a material is most often constituted by several components and each component (polymers, reinforcing organic or inorganic fibers, organic or mineral, inert or reactive flame retardants, various other additives...) undergoes pyrolysis according to its own rate. The pyrolysis rate of a component mainly depends on its thermal stability. It is expected that a less thermally stable component decomposes rather earlier and then its fraction decreases over time. Then the composition of the whole material changes continuously. A composition gradient exists from the surface exposed to the flame to the bulk and progresses over time. Of course, such a gradient cannot be deduced easily from analyses at microscale (like thermogravimetric analysis or pyrolysis-combustion flow calorimetry).

It would be very useful to distinguish the specific rates of each decomposition step in a complex material. Hence, the influence of one step on another one can be assessed and such information would allow tailoring better flame retardancy strategies. For example, it would be possible to better understand why polymer blends exhibit a complex behavior which cannot be simply

\footnotetext{
* Corresponding author.

E-mail address: rodolphe.sonnier@mines-ales.fr (R. Sonnier).
}

deduced from a linear rule of mixtures. Quite often, the peak of heat release rate (pHRR) of a blend in cone calorimeter is significantly lower than the expected value calculated from such a rule. As an example, Fig. 1 shows the pHRR of various ethylene methylacrylate copolymer/poly(butylene terephthalate) (EMA/PBT) blends in cone calorimeter test at $50 \mathrm{~kW} / \mathrm{m}^{2}$ (unpublished data). It can be observed that the 50/50 (in weight) blend exhibits a pHRR close to $600-650 \mathrm{~kW} / \mathrm{m}^{2}$ versus 1000 and $900 \mathrm{~kW} / \mathrm{m}^{2}$ for pure PBT and EMA respectively.

Cone calorimeter is a powerful tool to study the fire behavior of polymeric materials at bench scale [1-2]. During this test, the heating front moves vertically from the upper to the lower surface. If the material is thermally thick, a significant heat gradient appears through its thickness. The relatively simple test geometry allows calculating some important fire performances (as time-toignition or mass loss rate in steady state) from the material properties (emissivity, specific heat, thermal conductivity, density, temperature of ignition) and the test conditions (heat flux, heat transfer coefficient) [3-5]. These approaches have some important issues because they do not take into account several phenomena: indepth absorption [6], bubbling [7], heat distortion or sample breakdown [8-10] and the change of the material properties during the burning... Nevertheless, in most cases, they provide a valuable insight on the decomposition of materials.

But, to the best of our knowledge, materials tested in cone calorimeter test are always considered as homogeneous, i.e. no 


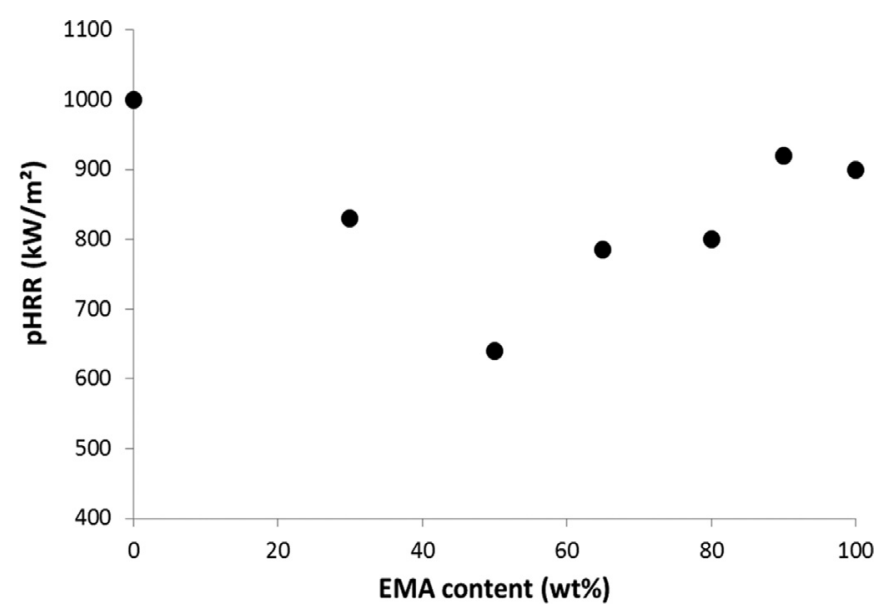

Fig. 1. Peak of heat release rate of EMA/PBT blends according to EMA content in cone calorimeter test (heat flux $50 \mathrm{~kW} / \mathrm{m}^{2}$ ).

attempt to distinguish the specific decomposition kinetics of different components has been performed. However, the different components in a thorough blend can decompose at different rates if their thermal stabilities are different. In fact, we assume that there are as many pyrolysis fronts as components.

To distinguish each pyrolysis front is a challenge except when one component (among two) is inert: in this case, the mass loss rate of the material is obviously only due to the second component. It is well-known that Fourier-transformed infrared spectroscopy (FTIR) analysis of gases can provide valuable information about the decomposition of materials. A great example is the use of TGA-FTIR experiments to study the pyrolysis of flame retarded poly(butylene terephthalate) reinforced by glass fibers [11-12]. Nevertheless, in cone calorimeter test, gases undergo oxidation in flame before FTIR analysis. Therefore, FTIR analysis cannot really help to identify gases from pyrolysis except before ignition [13]. Another method is then needed to follow the relative decomposition of each component in a material.

In this work, we propose a method to distinguish the decomposition rates in cone calorimeter for a material exhibiting only two decomposition steps. It includes two-layer composites, copolymers like ethylene-vinyl acetate, polymer blends, polymer containing hydrated fillers...

\section{Presentation of the method}

If we consider a material exhibiting two decomposition steps (for example two polymers degrading in one step), mass loss (ML) at each time is the sum of the mass losses from the first and the second steps. The whole mass loss rate is also the sum of the individual mass loss rates (Eq. 1). Identically, heat release rate can be divided in two parts: heat release rate corresponding to the first step and heat release rate corresponding to the second one (Eq. 2). Finally, each mass loss rate (MLR) is linked to the corresponding heat release rate (HRR) and effective heat of combustion (EHC) through Eq. 3.

$$
\begin{aligned}
& M L R=M L R_{\text {step } 1}+M L R_{\text {step } 2} \\
& H R R=H R R_{\text {step } 1}+H R R_{\text {step } 2} \\
& H R R_{i}=M L R_{i} \times E H C_{i}
\end{aligned}
$$

MLR and HRR are measured during the cone calorimeter test. If EHC of both decomposition steps are known and different enough, Eq. (2) can be modified to obtain a system of two Eqs. (1) and (4)) and two unknown variables ( $M L R_{\text {step } 1}$ and $\left.M L R_{\text {step 2 }}\right)$ at each time.

$$
H R R=M L R_{\text {step } 1} \times E H C_{\text {step } 1}+M L R_{\text {step } 2} \times E H C_{\text {step } 2}
$$

Effective heats of combustion in cone calorimeter test are generally close to the heats of complete combustion (except for halogenated materials). When it is not the case (for example poly(butylene terephthalate), the effective heat of combustion of a polymer in blend was chosen to be equal to the effective heat of combustion of the same pure polymer tested at the same heat flux.

Such a system can be perfectly resolved. Moreover, the calculations must fulfill Eqs. (5) and (6).

$\int M L R_{i}=M L_{i}$

$\int H R R=T H R$

with $T H R$ the total heat release.

We have attempted to apply this approach to various materials. In fact, other researchers have also used the change in effective heat of combustion to study deeply the flame retardancy of materials. Seefeldt and Braun have studied wood-plastic composites using cone calorimeter [14]. They assigned some changes in EHC during burning to water release or char oxidation. Kramer et al. have studied the burning of flexible polyurethane foams [15]. They calculated the effective heat of combustion of the two decomposition steps assigned to the decomposition of toluene-diisocyanate (TDI) and polyether respectively. Then they showed that the effective heat of combustion increases during the collapse of the foam in cone calorimeter test proving that the ratio of polyol consumed to TDI compounds increases during this step. Nevertheless to the best of our knowledge, it is the first time that this approach is systematically developed.

$M L R_{\text {step } 1}$ and $M L R_{\text {step } 2}$ during the whole cone calorimeter test were calculated using Solver from Excel to minimize the difference between the experimental and calculated HRR curves. Experimental HRR is measured every $5 \mathrm{~s}$. Average deviation between experimental and calculated heat release rate was calculated as follows:

Average deviation $=\frac{\left|H R R_{\text {exp }}-H R R_{\text {calc }}\right|}{\Delta t} \times 5$

with $\Delta t$ the duration of the test and $H R R_{\text {calc }}$ and $H R R_{\exp }$ the calculated and experimental heat release rates respectively.

Errors on EHC, mass losses and THR are also calculated. Errors $E$ were calculated as follows:

$E_{P}(\%)=\frac{\left|P_{\exp }-P_{\text {calc }}\right|}{P_{\exp }} \times 100$

with $P_{\exp }$ and $P_{\text {calc }}$ the experimental and calculated properties (EHC, ML or THR).

Table S1 in supporting information lists the different materials, the average deviation on HRR and the errors on THR and mass losses. It can be noted that errors are very low in most cases. Only three materials exhibit an error higher than 5\%, both on EHC and THR but errors on mass loss are much lower. Average deviation is often low and most often due to the deviation between calculated and experimental peak of HRR (see Figs. S1, S2 and S3). In the whole, calculated HRR fits quite well the experimental HRR data, except the sharp pHRR in some cases (see Figs. S1-S4). Average deviation for EMA/PBT 30/70 is rather high due to a shift between calculated and experimental HRR curves (Fig. S5).

In the following we will attempt to analyze results by considering two parameters. The first one is the ratio between the mass loss rate of the least thermally stable polymer (Pol-) and the mass 
Table 1

Materials and corresponding effective heats of combustion.

\begin{tabular}{llll}
\hline Materials & Grade & $\begin{array}{l}\text { Heat of complete } \\
\text { combustion }(\mathrm{kJ} / \mathrm{g})\end{array}$ & $\begin{array}{c}\text { Effective heat of combustion } \\
\text { in cone calorimeter (kJ/g) }\end{array}$ \\
\hline Wood & Unknown & 10.3 & 10.3 \\
Coating & Unknown & 25.9 & 25.9 \\
Ethylene vinyl-acetate & Escorene Ultra UL00226CC, Exxon Mobil & Step 1 17.8 & Step 1 16.1 \\
26 wt\% of vinyl acetate & & Step 2 40.9 & Step 2 36.9 \\
Ethylene vinyl-acetate & Alcudia PA440, Repsol & Step 1 17.8 & Step 1 16.1 \\
28wt\% of vinyl acetate & & Step 2 40.9 & Step 236.9 \\
Magnesium dihydroxide & Magnifin H10, Albemarle & 0 & 0 \\
Alumina & Prolabo (D50=28 $\mu$ m) & $/$ & $/$ \\
Kaolinite & Paralux, Imerys & $/$ & 36.3 \\
Ethylene methylacrylate & Lotryl 24MA005, Arkema & 36.3 & 18.7 \\
Polybutylene terephtalate & Vestodur 3000, Degussa & 20 & 42.5 \\
Low-density polyethylene & LDPE LD171 BA, Exxon Mobil & 42.5 & 28 \\
Polyamide 6 & C206, Technyl, Rodia Engineering & 28 & 20.5 \\
Polyhydroxybutyrate & Biocycle 1000, PHB industrial S/A & 20.5 & \\
\hline
\end{tabular}

loss rate of the most thermally stable one $(\mathrm{Pol}+)$ as presented in Eq. (9).

$R_{\text {deg }}=\frac{M L R_{\text {Pol- }}}{M L R_{\text {Pol+ }}}$

Average $R_{\text {deg }}$ is defined as the ratio between average mass loss rates of both polymers, calculated between 20 and $70 \mathrm{wt} \%$ of relative mass losses.

The second parameter $\Delta t_{10}$ is the difference between the time for the least stable polymer to reach a mass loss of $10 \%$ and the time for the most stable polymer to reach a mass loss of $10 \%$ Eq. (10).

$\Delta t_{10}=t_{10_{\text {Pol }+}}-t_{10_{\text {Pol }}}$

with $t_{10}$ is the time for $10 \%$ of mass loss.

Several issues limit the suitability of the method. First, the materials must decompose through only two steps exhibiting different and known effective heats of combustion. In particular, in presence of halogenated compounds and some phosphorus flame retardants, the combustion efficiency can decrease according to the release of halogenated gases in flame. Therefore, EHC varies continuously and the method is not convenient anymore.

It must also be noted that the instantaneous mass loss rate (and consequently the instantaneous effective heat of combustion) measured in cone calorimeter is not reliable. The values must be smoothed to calculate moving average on 5-10 data points. Therefore, the beginning of the curve is not well taken into account. Moreover, Solver from Excel is probably not the best software for the optimization and better fitting may be found using more efficient software. No attempt to compare different softwares was carried out. Nevertheless as proven in the following and considering errors in supporting information, the calculations satisfactorily fit HRR curves.

\section{Materials and calorimetry tests}

Various materials were tested in this study. Table 1 lists the different components and their heats of combustion in complete combustion (as measured using pyrolysis-combustion flow calorimetry) and in cone calorimeter test. Composites and blends were prepared by co-rotating twin-screw extruder (Clextral BC21, Firminy, France) and injection-molding machine (Krauss Maffei KM 50t). Conditions were chosen according to materials to be prepared. Dimensions are $100 \times 100 \times 4 \mathrm{~mm}^{3}$ for all specimens.

The pyrolysis combustion flow calorimetry (PCFC) from Fire Testing technology (UK) was used to assess the thermal stability of polymers and their heat of complete combustion. This device was developed by Lyon et al. [16]. The sample was first heated from 80
Table 2

List of studied materials and associated $\Delta t_{10}$ and average $R_{\text {deg. }}$.

\begin{tabular}{llrl}
\hline Materials & $\begin{array}{l}\text { Heat flux } \\
\left(\mathrm{kW} / \mathrm{m}^{2}\right)\end{array}$ & $\Delta t_{10}(\mathrm{~s})$ & $\begin{array}{l}\text { Experimental } \\
\text { average } R_{\text {deg }}\end{array}$ \\
\hline Coated wood & 50 & $/$ & $/$ \\
EMA/MDH 75/25 & 50 & 45 & 1.64 \\
EVA & 50 & 5 & 2.50 \\
EVA/alumina & 50 & 25 & 0.64 \\
EVA/kaolinite & 50 & 75 & 2.34 \\
EMA-PBT 80-20 & 50 & 25 & 1.38 \\
EMA-PBT 50-50 & 50 & 25 & 1.18 \\
EMA-PBT 30-70 & 50 & 120 & 0.39 \\
LDPE-PA6 50-50 & 35 & 10 & 0.93 \\
LDPE-PA6 50-50 & 50 & -10 & 1.24 \\
LDPE-PA6 50-50 & 75 & -15 & 1.34 \\
LDPE-PHB 50-50 & 35 & 85 & 1 \\
LDPE-PHB 50-50 & 50 & 55 & 0.97 \\
LDPE-PHB 50-50 & 75 & 15 & 0.86 \\
\hline
\end{tabular}

to $750{ }^{\circ} \mathrm{C}$ at $1{ }^{\circ} \mathrm{C} / \mathrm{s}$ in a pyrolyzer under nitrogen flow (anaerobic pyrolysis - method A according to the standard ASTM D7309) and the decomposition products were sent to a combustor where they mixed with oxygen in excess at $900^{\circ} \mathrm{C}$. Under such conditions, all gases were fully oxidized. Heat release rate (HRR) was then calculated by oxygen depletion according to Huggett's relation ( $1 \mathrm{~kg}$ of consumed oxygen corresponds to $13.1 \mathrm{MJ}$ of released energy) [17]. Effective heat of combustion was calculated as the total heat release divided by total mass loss.

A cone calorimeter from Fire Testing Technology (UK) was used. Horizontal sample of $100 \times 100 \times 4 \mathrm{~mm}^{3}$ was placed at $2.5 \mathrm{~cm}$ below a conic heater and was exposed to various heat fluxes in well-ventilated conditions (air rate $24 \mathrm{~L} / \mathrm{s}$ ) and in the presence of a spark igniter to force the ignition. As in PCFC test, HRR was determined according to oxygen depletion (Huggett's relation [17]). This test was performed according to the ISO 5660 standard.

\section{Experimental results}

Table 2 lists the materials studied and the corresponding values of $\Delta t_{10}$ and average $R_{\text {deg. }}$. The first material (coated wood) is not a thorough blend but a two-layer composite. Then these parameters have not been calculated.

\subsection{Coated wood two-layer composite}

The first example is a composite constituting by an $18 \mathrm{~mm}$-thick wood layer coated by a $3 \mathrm{~mm}$ varnish layer (Fig. 2). The exact nature of both materials is unknown but their main flammability properties were measured using PCFC. Effective heats of combustion are 10.3 and $25.9 \mathrm{~kJ} / \mathrm{g}$ for wood and coating respectively. 


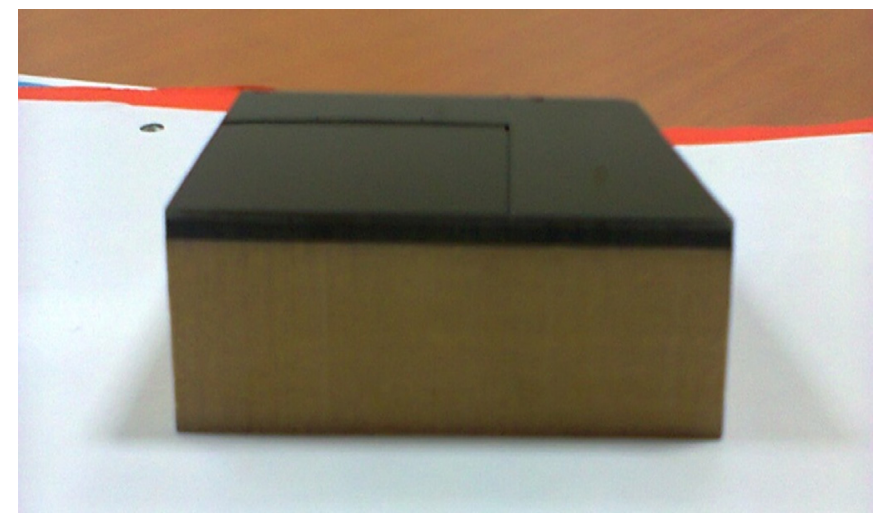

Fig. 2. Coated wood two-layer composite (coating has already been partially decomposed on the picture).

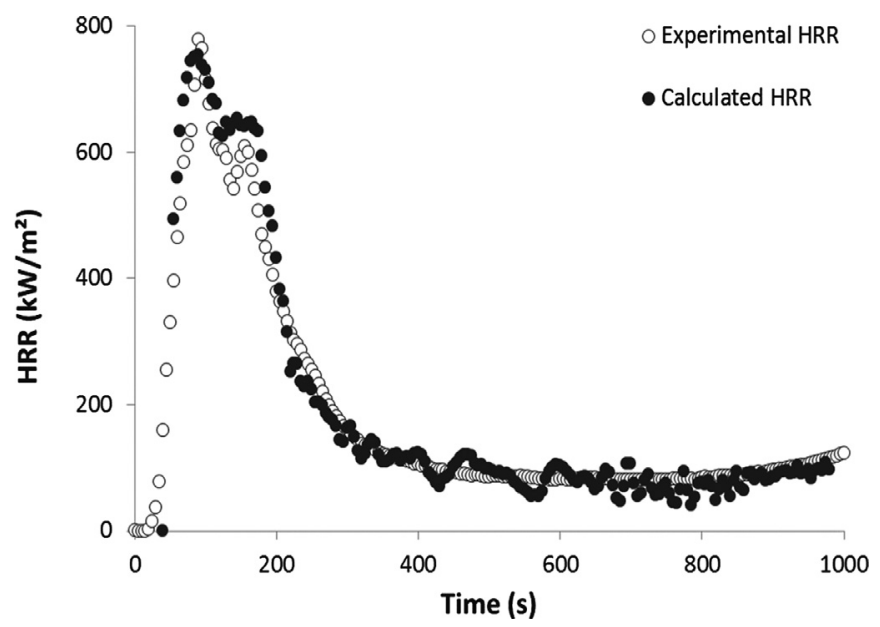

Fig. 3. Experimental and calculated HRR for coated wood composite in cone calorimeter at $50 \mathrm{~kW} / \mathrm{m}^{2}$.

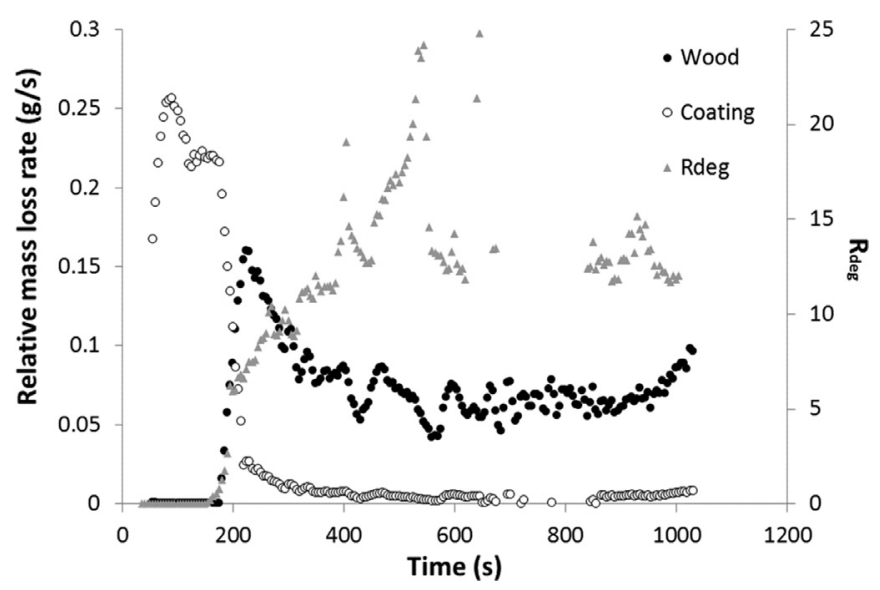

Fig. 4. Calculated MLR for coating and wood and $R_{\text {deg }}$ in cone calorimeter at $50 \mathrm{~kW} / \mathrm{m}^{2}$.

In cone calorimeter, the heat front moves from the upper to the lower surfaces. Then the coating is expected to be firstly decomposed before wood. Figures 3 and 4 represent respectively the experimental and calculated HRR curves and the relative mass losses for both components. $R_{\text {deg }}$ is defined for this material as the ratio between the mass loss rate of the wood and the mass loss rate of coating. As expected, the calculated mass loss rates show that only the coating is degrading during the first $180 \mathrm{~s}$. The ratio $R_{\text {deg }}$ is close to 0 . At $180 \mathrm{~s}$, more than $80 \%$ of the coating is already

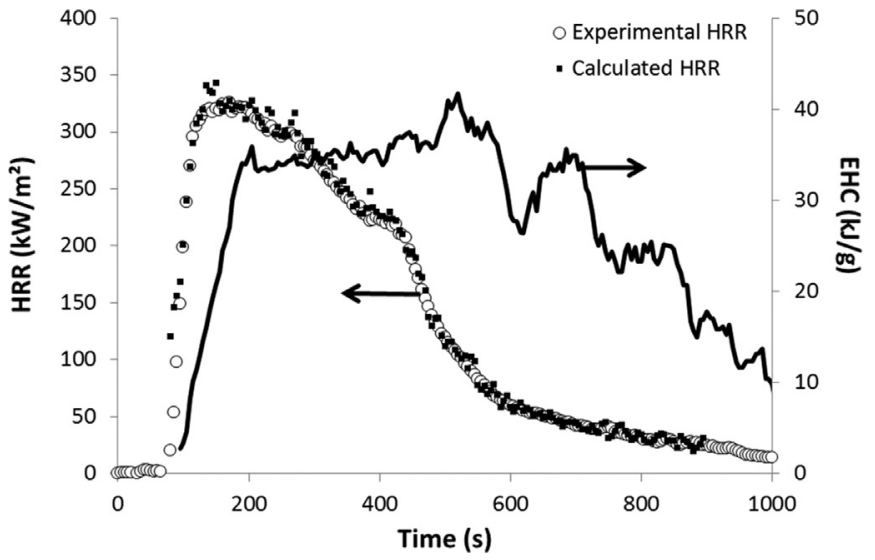

Fig. 5. Experimental and calculated HRR and experimental EHC for EMA/MDH $75 / 25$ in cone calorimeter at $50 \mathrm{~kW} / \mathrm{m}^{2}$.

decomposed. Then a sudden decrease of its relative mass loss rate occurs while the relative mass loss rate of the wood layer starts increasing. The mass loss rate of wood stabilizes around $0.07 \mathrm{~g} / \mathrm{s}$ after $300 \mathrm{~s}$. $R_{\text {deg }}$ becomes very high. Its real value may be infinite but the optimization by Solver from Excel calculates a non-null but negligible mass loss rate for coating. A good agreement between experimental and calculated HRR is found.

This simple example proves that our method is able to fit accurately the expected and quite obvious behavior of a multi-layers composite. It may give new insights on fire behavior of laminated materials. Indeed, some works have been carried out to locate the flame retardants (FR) into a layer at the top surface of the material in order to improve the FR efficiency without compromising the mechanical properties [18-20]. Such a strategy seems to be a promising approach for flame retardancy.

Then it is now possible to use it to fit the behavior of homogeneous (i.e. not multi-layered) blends.

\subsection{EMA filled with magnesium dihydroxide}

Ethylene-methylacrylate is a copolymer exhibiting only one decomposition step centered on $470^{\circ} \mathrm{C}$. Its effective heat of complete combustion is $36.3 \mathrm{~kJ} / \mathrm{g}$. Its effective heat of combustion in cone calorimeter at $50 \mathrm{~kW} / \mathrm{m}^{2}$ is also $36.3 \mathrm{~kJ} / \mathrm{g}$, that means its combustion is complete. Magnesium dihydroxide is a hydrated filler releasing $31 \%$ of water around $350^{\circ} \mathrm{C}$. The "effective heat of combustion" of the released gases is obviously equal to $0 \mathrm{~kJ} / \mathrm{g}$. $\mathrm{MDH}$ does not act as charring promoter in EMA. Its main effects are only gases dilution, cooling of the condensed phase through an endothermic decomposition and barrier effect by accumulation of magnesium oxide on the polymer surface [21].

EMA/MDH 75/25 blend can be considered as a two-step degrading blend: one step corresponds to the release of water by MDH and a second step is the decomposition of EMA. Experimental and calculated HRR and experimental EHC in cone calorimeter at $50 \mathrm{~kW} / \mathrm{m}^{2}$ are given in Fig. 5 for this blend. It can be seen that EHC increases faster up to $33 \mathrm{~kJ} / \mathrm{g}$ at $200 \mathrm{~s}$. Then EHC increases more slowly up to around $38 \mathrm{~kJ} / \mathrm{g}$. The decrease at the end of the test (after $600 \mathrm{~s}$ ) is not very reliable due to the very low mass loss rate. Calculated heat release rate curve is very close to the experimental one. Calculated THR is only slightly higher than experimental THR (131 MJ/m² versus $126 \mathrm{MJ} / \mathrm{m}^{2}$ ). Calculated mass losses for EMA and MDH perfectly fit the theoretical mass losses (according to the initial composition). Calculated mean effective heat of combustion is equal to the experimental one $(32.9 \mathrm{~kJ} / \mathrm{g})$. Then our modeling can be considered as satisfactory. 


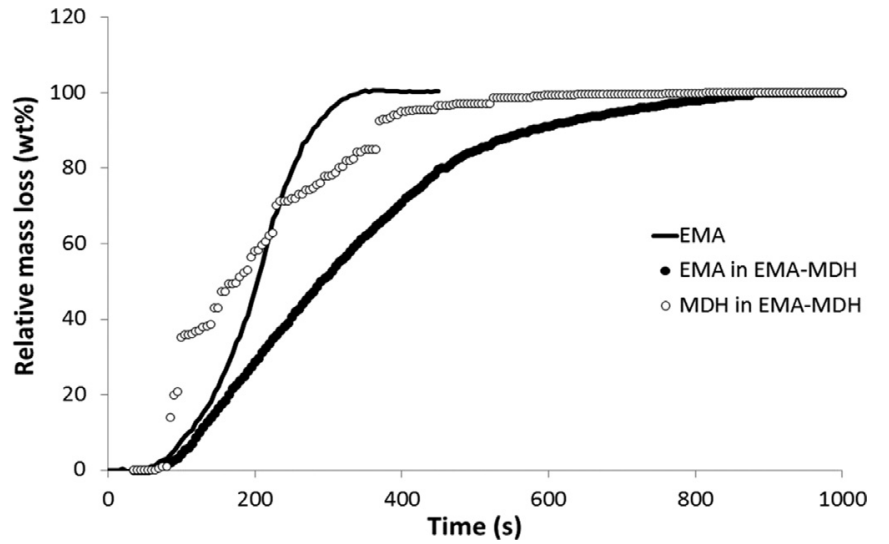

Fig. 6. Relative mass loss rates for pure EMA, EMA in EMA/MDH 75/25 and MDH in $\mathrm{EMA} / \mathrm{MDH} 75 / 25$ in cone calorimeter $\left(50 \mathrm{~kW} / \mathrm{m}^{2}\right)$.

The fast then slow increase of EHC means that the ratio between EMA and MDH mass loss rates increases during the test. It is not surprising while the thermal stability for EMA is significantly higher than for $\mathrm{MDH}$. This change is well observed when relative mass losses for EMA and MDH are calculated (Fig. 6). The decomposition of MDH is faster than EMA decomposition at the beginning and both mass loss rates are roughly similar up to $400 \mathrm{~s} . \Delta t_{10}$ is $45 \mathrm{~s} .50 \mathrm{wt} \%$ of $\mathrm{MDH}$ is decomposed after $180 \mathrm{~s}$ while $50 \mathrm{wt} \%$ of EMA is decomposed after $290 \mathrm{~s}$. After $400 \mathrm{~s}$, MDH is fully decomposed. Then average $R_{d e g}(1.64)$ is much higher than the theoretical value calculated from the composition (25/75).

The early release of water at the beginning of the test has been already noted by different authors. For example, Hoffendahl et al. have studied EVA flame retarded with aluminum trihydroxide (ATH) and melamine borate [22]. They have calculated that $15 \%$ of water has already released before ignition in cone calorimeter test. Zhang et al. [23] have proposed to correct heat release rate by taking into account the decomposition heat of hydrated fillers. Nevertheless, their proposal was not acceptable because they corrected the whole HRR curve by a constant factor. Our method shows that it is possible to assess the true decomposition rate of hydrated filler and then to use the method proposed by Zhang et al. to correct adequately the HRR curve.

Comparison of mass loss rate of EMA in pure EMA and in EMA/MDH is also very interesting. The mass loss rates are more or less similar up to $180 \mathrm{~s}$ (the decomposition starts only few seconds later for EMA in EMA-MDH because ignition occurs later - $71 \mathrm{~s}$ versus $52 \mathrm{~s}$ ). But after $180 \mathrm{~s}$, the mass loss rate of EMA in EMA/MDH is stable or decreases slowly continuously. On the contrary, pure EMA decomposition is accelerated. This change in behavior occurs after $180 \mathrm{~s}$, i.e. when more than half MDH is already decomposed. Moreover, when MDH is fully decomposed, EMA mass loss rate does not accelerate. Then the stabilization of EMA mass loss rate in EMA/MDH may not be assigned to the cooling of condensed phase through endothermic decomposition of $\mathrm{MDH}$. We assume that this stabilization should be rather assigned to the accumulation of magnesium oxide on the specimen surface leading to a barrier insulating layer.

\subsection{EVA copolymer}

Ethylene-vinyl acetate is a copolymer degrading in two steps. The first one corresponds to the release of acetic acid and the second one to the decomposition of the polyene structure formed after the first step. In our case, the content of vinyl acetate is $26 \mathrm{wt} \%$. Both steps occur at different temperatures - around $300-350^{\circ} \mathrm{C}$ for the release of acetic acid and $470{ }^{\circ} \mathrm{C}$ for the second step in

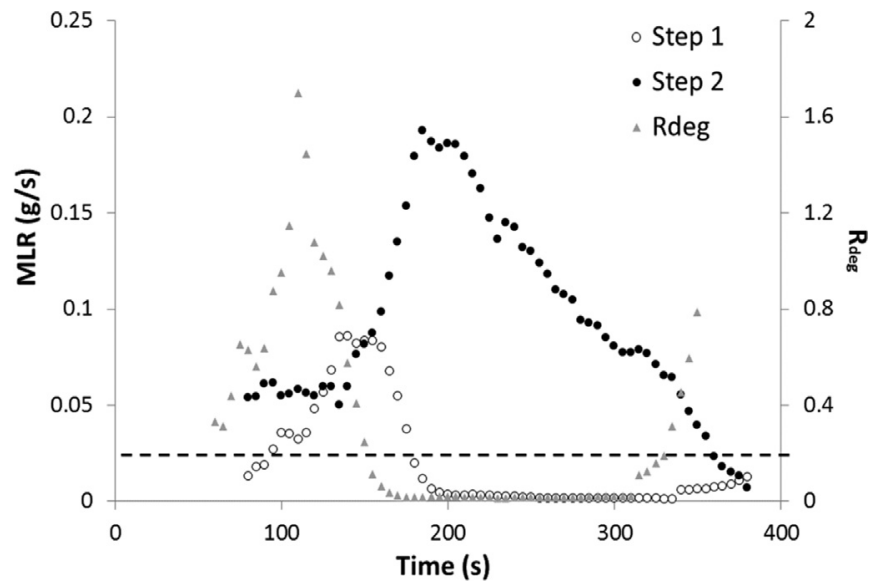

Fig. 7. Calculated MLR for the two decomposition steps of EVA and $R_{\text {deg }}$ in cone calorimeter at $50 \mathrm{~kW} / \mathrm{m}^{2}$ (dotted line corresponds to theoretical $R_{\text {deg }}$ calculated according to the composition).

PCFC. Moreover, the effective heats of combustion are very different: $17.8 \mathrm{~kJ} / \mathrm{g}$ for the first step and $40.9 \mathrm{~kJ} / \mathrm{g}$ for the second one in PCFC. The effective heat of complete combustion is then $36.7 \mathrm{~kJ} / \mathrm{g}$. In cone calorimeter at $50 \mathrm{~kW} / \mathrm{m}^{2}$, the experimental EHC is only $33.2 \mathrm{~kJ} / \mathrm{g}$, i.e. the combustion efficiency is $90 \%$. Then we have considered the EHC of both steps in cone calorimeter are equal to 16.1 and $36.9 \mathrm{~kJ} / \mathrm{g}$ respectively. This assumption is questionable: the combustion efficiency of gases over temperature may be different even when these gases are released from the same polymer [24].

Total heat release calculated according to our method is very close to the experimental one (134.9 and $134.6 \mathrm{~kJ} / \mathrm{g}$ respectively). Calculated mass losses for the first and the second steps of decomposition are 6.2 and $29.6 \mathrm{wt} \%$, very close to the theoretical values (6.4 and $29.4 \mathrm{wt} \%$ ).

As expected, the first decomposition step obviously occurs before the second one. The theoretical mean ratio between mass loss rates $\left(R_{\text {deg }}\right)$ is 0.2 according to the composition (Fig. 7). During the first $150 \mathrm{~s}$, its real value is much higher than this average. Experimental average $R_{\text {deg }}$ is 2.5 . The peak of mass loss rate is reached after $150 \mathrm{~s}$ for the first step, and $190 \mathrm{~s}$ for the second one. After $200 \mathrm{~s}$, the first step is completed, i.e. that the temperature may be higher than around $350^{\circ} \mathrm{C}$ in the whole specimen (even in the bottom layer). The early release of acetic acid has already been shown by various authors. Hoffendahl et al. have calculated that $81 \%$ of acetic acid is released before ignition in the case of EVA filled with ATH and melamine borate [22]. Zanetti et al. have also observed that EVA decomposition shows two overlapping steps in cone calorimeter and they assigned the first one mainly to deacetylation [25].

We have also studied two EVA copolymers containing alumina or kaolinite fillers. In these composites EVA contains $28 \mathrm{wt} \%$ of vinyl acetate but the effective heats of combustion of steps 1 and 2 are kept constant. The content of filler is $50 \mathrm{wt} \%$. Alumina is thermally stable and kaolinite releases water only at high temperatures (around $500^{\circ} \mathrm{C}$ ). In this last case, we have considered that kaolinite does not release water during cone calorimeter test. This assumption is not fully verified and experimental effective heat of combustion is slightly lower than calculated $(31.5 \mathrm{~kJ} / \mathrm{g}$ versus $33.2 \mathrm{~kJ} / \mathrm{g})$. Despite this approximation, a quite good agreement between experimental and calculated HRR data is obtained. Figure 8 shows the experimental and calculated HRR curves for both samples.

The relative mass losses of both decomposition steps for EVA have also been plotted in EVA filled with $50 \mathrm{wt} \%$ of alumina or kaolinite. The first step of decomposition is slowed down in presence of fillers but there is no significant difference between EVA/alumina and EVA/kaolinite (see Fig. S6 in supporting 


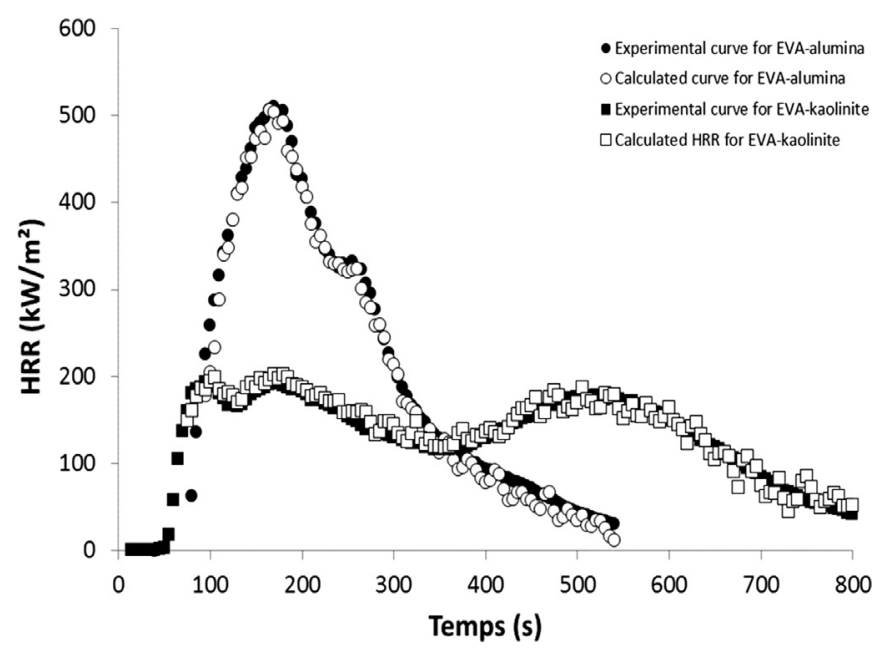

Fig. 8. Experimental and calculated HRR for EVA/alumina 50/50 and EVA/kaolinite $50 / 50$ in cone calorimeter at $50 \mathrm{~kW} / \mathrm{m}^{2}$.

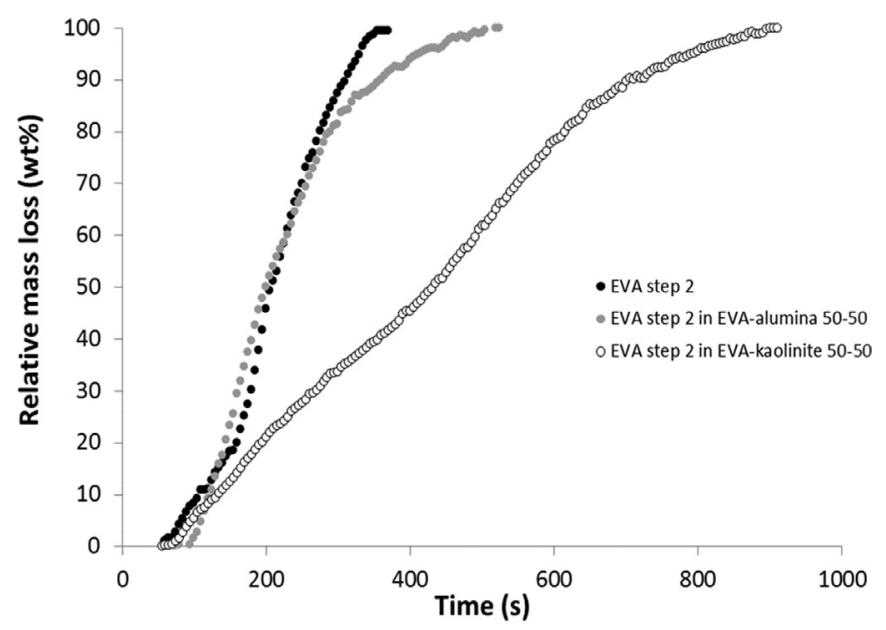

Fig. 9. Relative mass loss rates for the second decomposition step of EVA in pure EVA and EVA filled with $50 \mathrm{wt} \%$ of alumina and kaolinite in cone calorimeter $\left(50 \mathrm{~kW} / \mathrm{m}^{2}\right)$.

information). The shift between both curves is due to the fact that ignition occurs earlier for EVA/kaolinite. Very interestingly, the mass loss rate for the second step of decomposition is similar for pure EVA and EVA-alumina but much reduced for EVA-kaolinite (Fig. 9). It has been assumed that kaolinite improves the flame retardancy of EVA through barrier effect monitored by the high viscosity of the sample [26]. In this formulation, the decrease of mass loss rate for the first decomposition step is relatively low in comparison to the very efficient slowdown of the second step. It may be assumed that the barrier effect due to the accumulation of kaolinite particles on the sample surface is able to maintain during a long time the temperature in the condensed phase mainly in the range $350-450{ }^{\circ} \mathrm{C}$, i.e. the temperature reaches quickly $300-350{ }^{\circ} \mathrm{C}$ (allowing the first decomposition step to occur) but more slowly $450-500^{\circ} \mathrm{C}$ corresponding to the temperature range of the second decomposition step.

$\Delta t_{10}$ and average $R_{\text {deg }}$ change drastically for these three materials. $\Delta t_{10}$ slightly increases with alumina but the increase is very significant with kaolinite due to the slowdown of the second decomposition step. Alumina slows down the mass loss rate for the first step but not for the second one. Therefore, $R_{\text {deg }}$ decreases strongly (but remains higher than the theoretical one: 0.64 versus

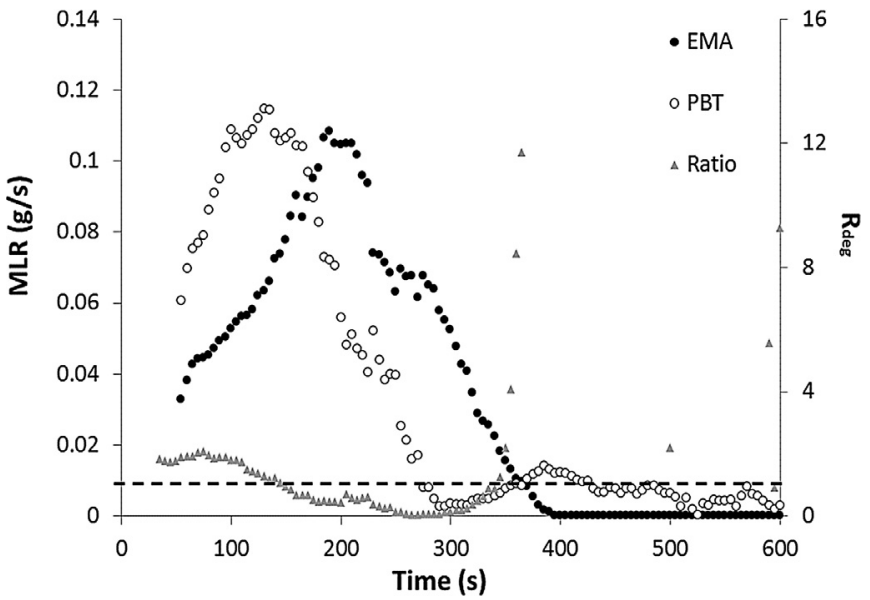

Fig. 10. Calculated MLR for EMA and PBT in EMA/PBT 50/50 and $R_{\text {deg }}$ in cone calorimeter at $50 \mathrm{~kW} / \mathrm{m}^{2}$ (dotted line corresponds to the theoretical $R_{\text {deg }}$ calculated according to the composition).

0.2 ). Kaolinite slows down both decomposition steps similarly: $R_{\text {deg }}$ remains close to the value observed for pure EVA (2.34 versus 2.5 ).

\subsection{EMA/PBT blends: influence of the composition}

Pure EMA and PBT and various EMA/PBT blends (80/20, 50/50 and $30 / 70$ ) were studied using cone calorimeter at $50 \mathrm{~kW} / \mathrm{m}^{2}$. EMA exhibits high effective heat of combustion of $36.3 \mathrm{~kJ} / \mathrm{g}$ in PCFC and in cone calorimeter. PBT exhibits a quite low EHC in cone calorimeter $(18.7 \mathrm{~kJ} / \mathrm{g})$ in comparison to PCFC $(20 \mathrm{~kJ} / \mathrm{g})$. Then the combustion efficiency is only 0.94 . Such a value was already obtained in a previous study about PC/PBT blends [27]. PBT is slightly charring - around 7-8\% depending on the delay between the flame out and the end of the test because the char is slowly decomposed by thermo-oxidation. We have considered that PBT is able to char also in blends. It is quite reasonable: a blend 50-50 exhibits char content close to 3-3.5 wt\%. Thermal stability of EMA and PBT (according to the temperature of the pHRR in PCFC) is 470 and $420^{\circ} \mathrm{C}$ respectively.

Good agreement was found between calculated and experimental HRR for the three blends. The worst fitting is obtained for the blend $50 / 50$ with an error of $7.2 \%$ on THR (Fig. S4). Nevertheless we assume the calculated curve is quite satisfactory.

As expected from their respective thermal stabilities, PBT starts degrading earlier than EMA (Fig. 10), as proved by the value of $\Delta t_{10}(25 \mathrm{~s})$. Up to $150 \mathrm{~s}, R_{\text {deg }}$ is higher than the theoretical $R_{\text {deg }}$ calculated according to the composition (i.e. 1). The peak of mass loss rate for PBT is reached after $130 \mathrm{~s}$ and $190 \mathrm{~s}$ for EMA. After $150 \mathrm{~s}$, the most part of PBT is already decomposed and $R_{d e g}$ becomes lower than 1. Similar results are obtained for EMA/PBT 80/20 and 30/70: $R_{\text {deg }}$ is always higher than the theoretical $R_{\text {deg }}$ (respectively 0.25 and 2.3) at the beginning of the test and the peak of mass loss rate for PBT is always reached before the peak of mass loss rate for EMA. Nevertheless, $\Delta t_{10}$ is significantly higher for EMA/PBT 30/70 ( $120 \mathrm{~s}$ versus $25 \mathrm{~s}$ ) and average $R_{\text {deg }}$ is very low (lower than the theoretical $R_{\text {deg }}$ : 0.39 versus 2.3 ).

Figures 11 and 12 show the relative mass losses in pure polymers and blends for EMA and PBT respectively. It can be observed that the mass loss rate of EMA is very similar in pure EMA and in EMA/PBT blends $80 / 20$ and 50/50. In other words, when EMA is the matrix, its decomposition rate is not really modified by the presence of PBT nodules.

On the contrary, when PBT is the matrix, EMA mass loss rate changes strongly: the decomposition starts very slowly during almost $100 \mathrm{~s}$ and then accelerates ( $\Delta t_{10}$ is $120 \mathrm{~s}$ ). This may be due to 


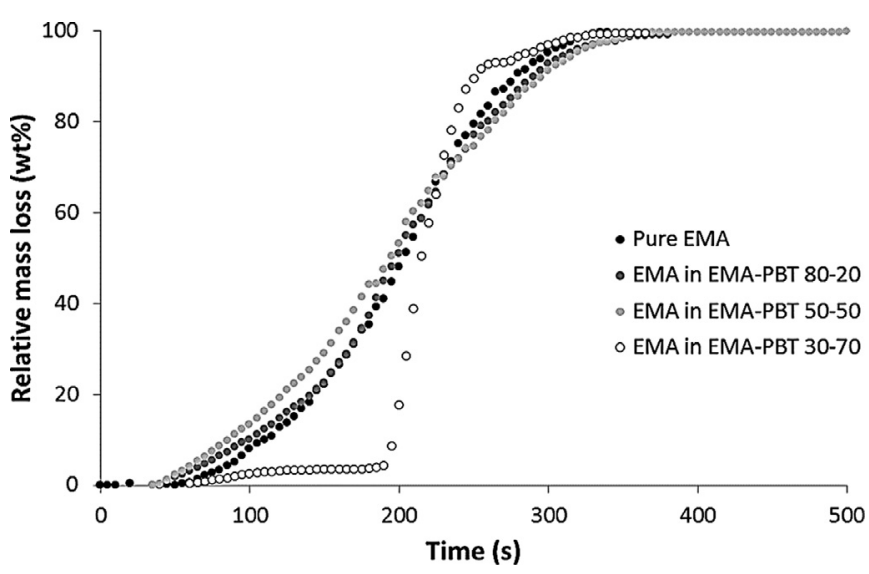

Fig. 11. Relative mass loss rates for EMA in pure EMA and EMA/PBT blends in cone calorimeter $\left(50 \mathrm{~kW} / \mathrm{m}^{2}\right)$.

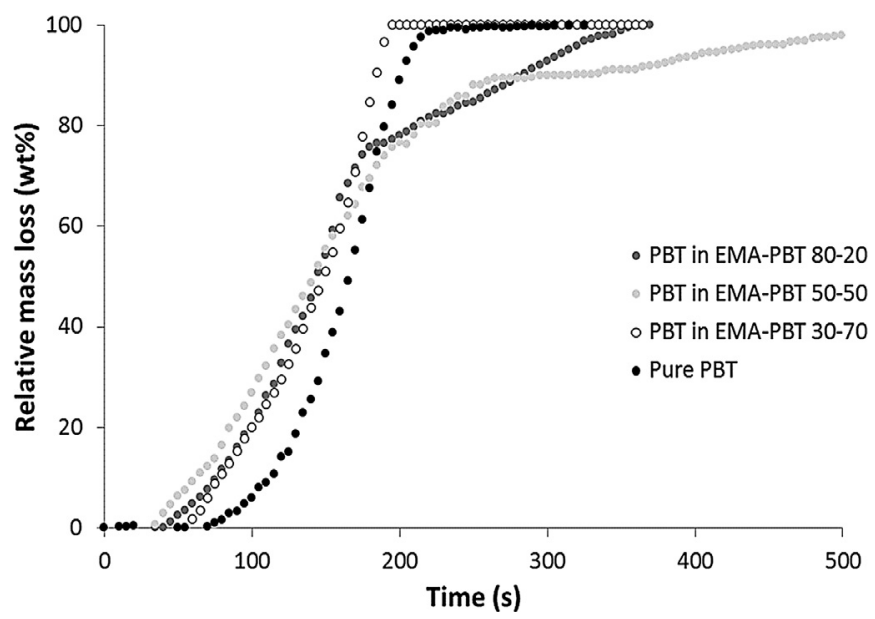

Fig. 12. Relative mass loss rates for PBT in pure PBT and EMA/PBT blends in cone calorimeter $\left(50 \mathrm{~kW} / \mathrm{m}^{2}\right)$.

the fact that the pyrolysis front is piloted by the matrix (i.e. PBT). Then the temperature remains close to the pyrolysis temperature of PBT and does not increase up to a value high enough to promote the fast decomposition of EMA. When PBT is almost fully decomposed, the mass loss rate of EMA increases very fast because the temperature can increase and EMA is already at high temperature (i.e. PBT pyrolysis temperature) in the whole sample. Therefore average $R_{\text {deg }}$ is very low. Patel et al. have shown that a high thermal conductivity delays the ignition but promotes heat buildup within the system leading to a higher heat release rate later [28].

On the contrary, the mass loss rate of PBT in blends seems to be rather constant or slightly lower than its value for pure PBT. The decomposition of PBT in blends starts earlier than in pure PBT. Then it may be considered that less heat is built up within the specimen when decomposition starts. Consequently the mass loss rate may be slightly lower.

Figure 13 summarizes the mass loss rates for EMA and PBT in pure polymers and blends. Mass loss rates were measured between $20 \%$ and $70 \%$ of relative mass loss. Even when relative mass loss rate for PBT is lower than for EMA, do not forget that PBT starts degrading before EMA. We can now explain why EMA/PBT 50/50 exhibits a lower pHRR than expected (i.e. lower than the value calculated from a linear rule of mixtures). Not only the peaks of mass loss rate of both polymers are not reached at the same time but their values are lower than in pure EMA or PBT (except the mass loss rate of EMA in EMA/PBT 30/70).

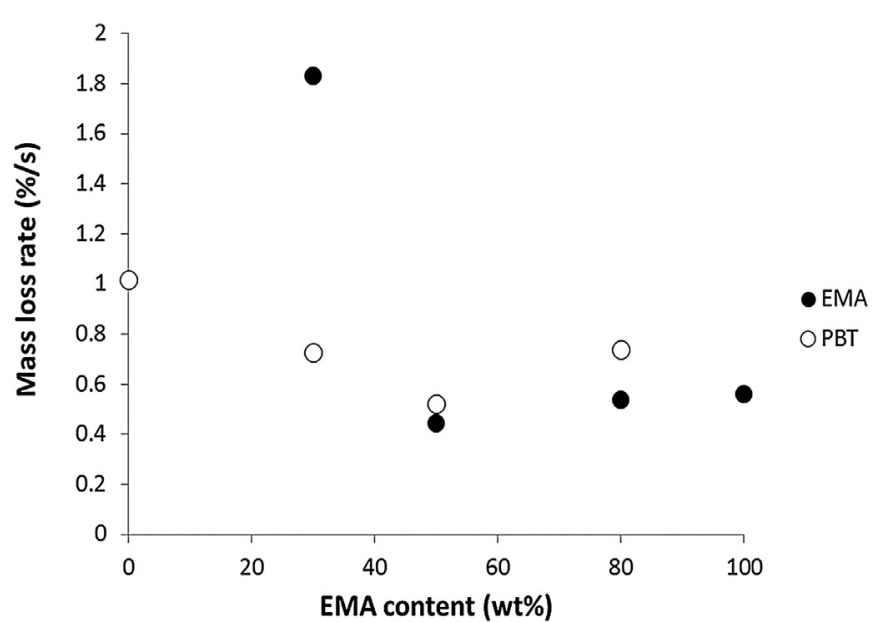

Fig. 13. Relative mass loss rates for EMA and PBT in pure polymers and various EMA/PBT blends in cone calorimeter $\left(50 \mathrm{~kW} / \mathrm{m}^{2}\right)$.

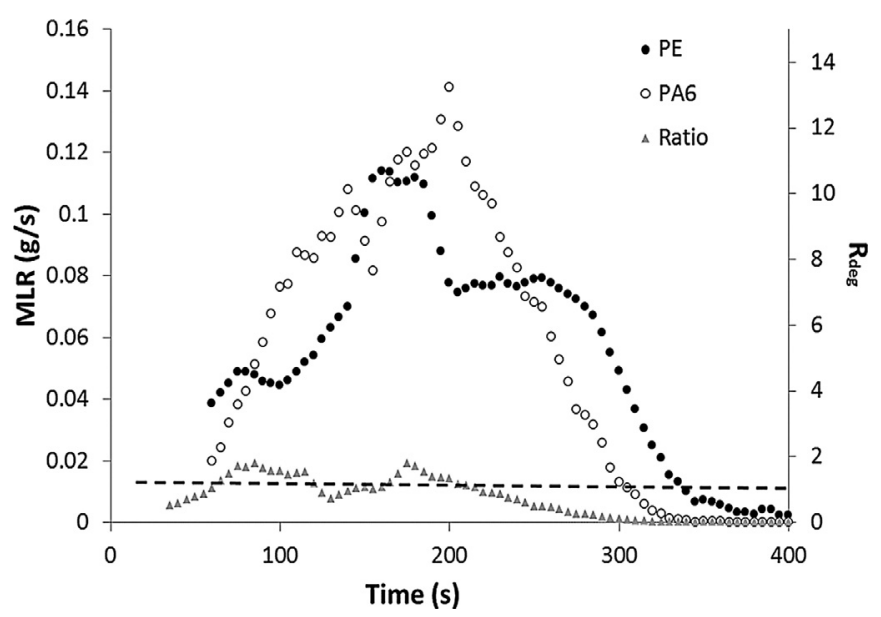

Fig. 14. Calculated MLR for LDPE and PA6 in PE/PA6 50/50 and $R_{\text {deg }}$ in cone calorimeter at $50 \mathrm{~kW} / \mathrm{m}^{2}$ (dotted line corresponds to the theoretical average $R_{\text {deg }}$ calculated according to the composition).

\subsection{LDPE/PA6 and LDPE/PHB 50/50 blends: influence of the heat flux}

Two blends were studied at various heat fluxes $(35,50$, $75 \mathrm{~kW} / \mathrm{m}^{2}$ ). The first one is LDPE/PA6 50/50. Both polymers exhibit quite similar thermal stability: pHRR in PCFC is observed at 470 and $490{ }^{\circ} \mathrm{C}$ respectively for PA6 and LDPE. On the contrary, LDPE and $\mathrm{PHB}$ from the second blend have very different thermal stability. Indeed, PHB is probably one of the least thermally stable synthetic polymers. Its pHRR in PCFC occurs at $310^{\circ} \mathrm{C}$. Effective heats of complete combustion of these three polymers are different enough to allow decoupling of their mass loss rates: $42.5 \mathrm{~kJ} / \mathrm{g}$ for LDPE, $28 \mathrm{~kJ} / \mathrm{g}$ for PA6 and $20.5 \mathrm{~kJ} / \mathrm{g}$ for PHB. The effective heats of combustion in cone calorimeter were chosen equal to these values, assuming a complete combustion. Experimental effective heats of combustion of blends were found in very good agreement with this assumption: $35.5 \mathrm{~kJ} / \mathrm{g}$ for LDPE/PA6 $50 / 50$ and $31.9 \mathrm{~kJ} / \mathrm{g}$ for LDPE/PHB 50/50 versus theoretical EHC equal to 35.3 and $31.5 \mathrm{~kJ} / \mathrm{g}$ respectively.

Figure 14 shows the relative mass losses for both polymers and the ratio $R_{d e g}$ when LDPE/PA6 is tested at $50 \mathrm{~kW} / \mathrm{m}^{2}$. It can be observed that $R_{d e g}$ is close to 1 up to 200 s, i.e. the mass loss rates of both polymers are roughly similar during the most part of burning. They increase together in the first part of the test and they reach both their peaks in the range 150-200 s. These observations were 


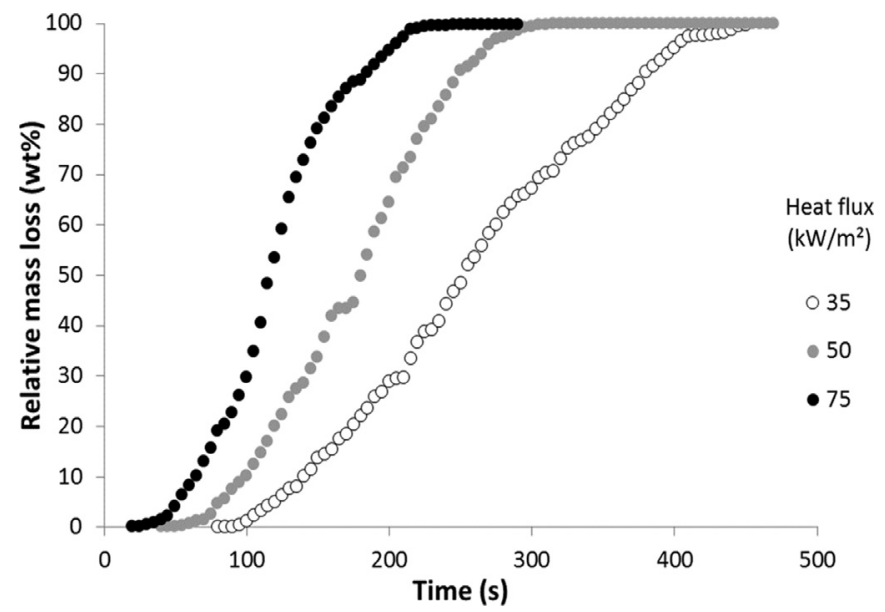

Fig. 15. Relative mass loss rates for PA6 in LDPE/PA6 blends in cone calorimeter at various heat fluxes.

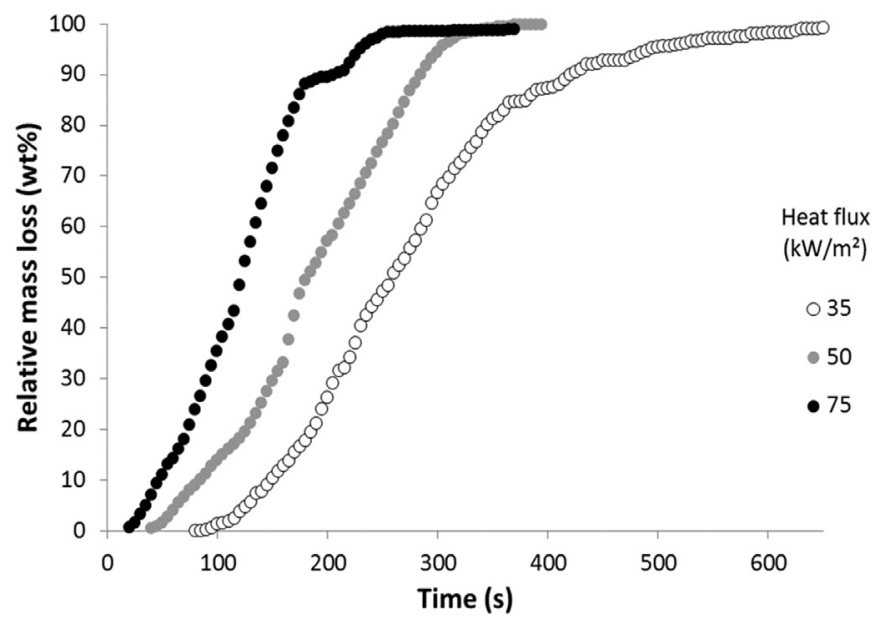

Fig. 16. Relative mass loss rates for LDPE in LDPE/PA6 blends in cone calorimeter at various heat fluxes.

also made for the tests at 35 and $75 \mathrm{~kW} / \mathrm{m}^{2}$. It can be noted that the mass loss rate of LDPE increases sharply after $140 \mathrm{~s}$ and decreases suddenly after $180 \mathrm{~s}$. This change was reproducible but not observed for tests at 35 and $75 \mathrm{~kW} / \mathrm{m}^{2}$.

Figures 15 and 16 represent the relative mass losses at various heat fluxes for PA6 and LDPE respectively. As expected mass loss rates increase when heat flux increases for both polymers. More interestingly, the comparison between both figures shows that relative mass losses are quite similar for both polymers at similar heat flux. For example mass loss reaches $50 \mathrm{wt} \%$ at 35, 50 and $75 \mathrm{~kW} / \mathrm{m}^{2}$ after 255, 185 and $120 \mathrm{~s}$ for PA6 and 260, 185 and $125 \mathrm{~s}$ for LDPE. While PA6 and LDPE exhibit close thermal stabilities, their decomposition rate in cone calorimeter test is very similar. $\Delta t_{10}$ is close to 0 and average $R_{\text {deg }}$ is in the range 0.93-1.34 (close to 1 ) in the three cases.

The behavior of LDPE/PHB 50/50 is completely different. Figure 17 shows the relative mass loss rates for both polymers and the ratio $R_{\text {deg }}$. Contrarily to the previous blend, one polymer (PHB) decomposes much earlier than the other one (LDPE). $\Delta t_{10}$ is higher than for LDPE/PA6 blends. $R_{\text {deg }}$ remains higher than 1 up to $150 \mathrm{~s}$ when approximately $80 \%$ of PHB is already decomposed. The delay between both peaks of mass loss rate is also relatively high: $55 \mathrm{~s}$. These observations are confirmed at other heat fluxes (35 and $75 \mathrm{~kW} / \mathrm{m}^{2}$ ).

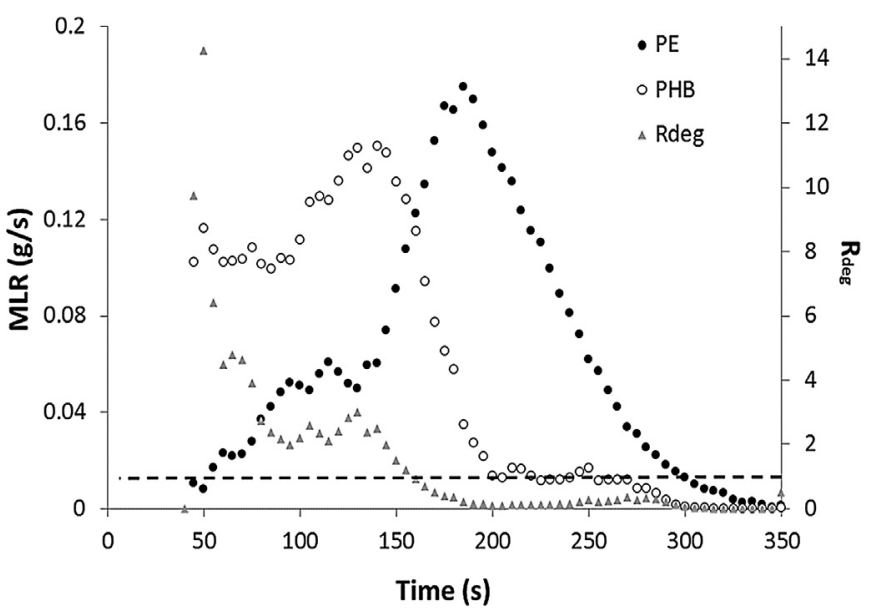

Fig. 17. Calculated MLR for LDPE and PHB in LDPE/PHB 50/50 and $R_{\text {deg }}$ in cone calorimeter at $50 \mathrm{~kW} / \mathrm{m}^{2}$ (dotted line corresponds to the theoretical average $R_{\text {deg }}$ calculated according to the composition).

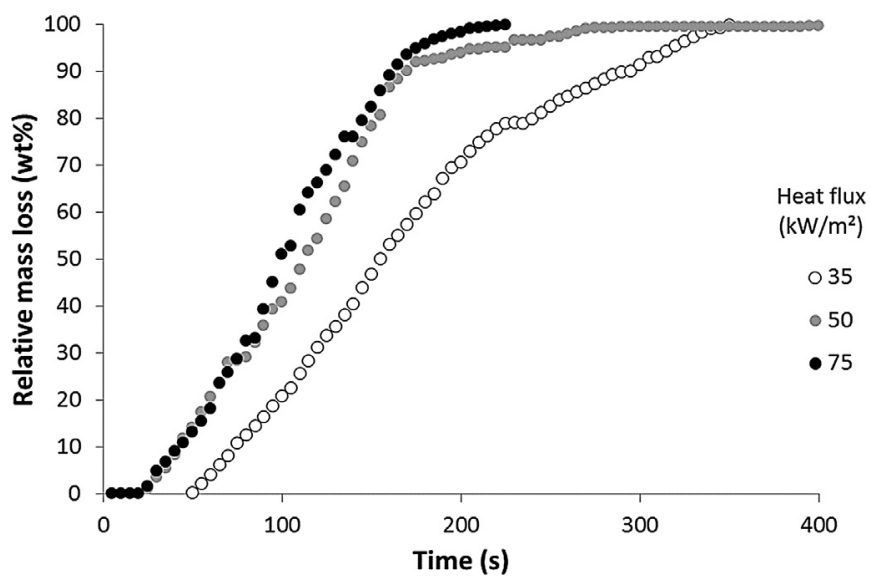

Fig. 18. Relative mass loss rates for PHB in LDPE/PHB blends in cone calorimeter at various heat fluxes.

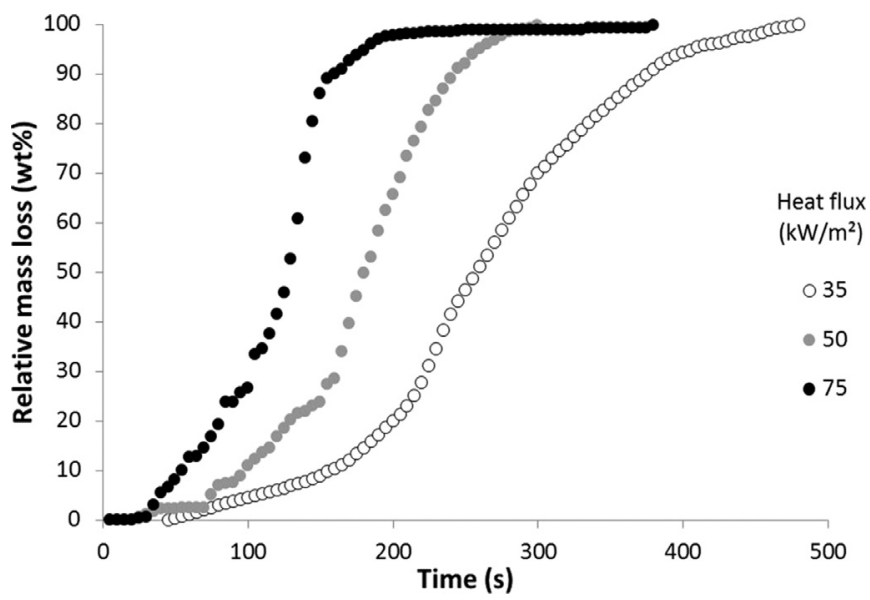

Fig. 19. Relative mass loss rates for LDPE in LDPE/PHB blends in cone calorimeter at various heat fluxes.

Figures 18 and 19 show the relative mass losses at various heat fluxes for PHB and LDPE respectively. The relative mass loss rate of LDPE increases progressively when heat flux increases as already observed for LDPE/PA6 blends. On the contrary, relative mass loss rate is similar for PHB at 50 and $75 \mathrm{~kW} / \mathrm{m}^{2}$. It is due to the fact that ignition occurs very quickly in both cases (25 and $12 \mathrm{~s}$ ): PHB 


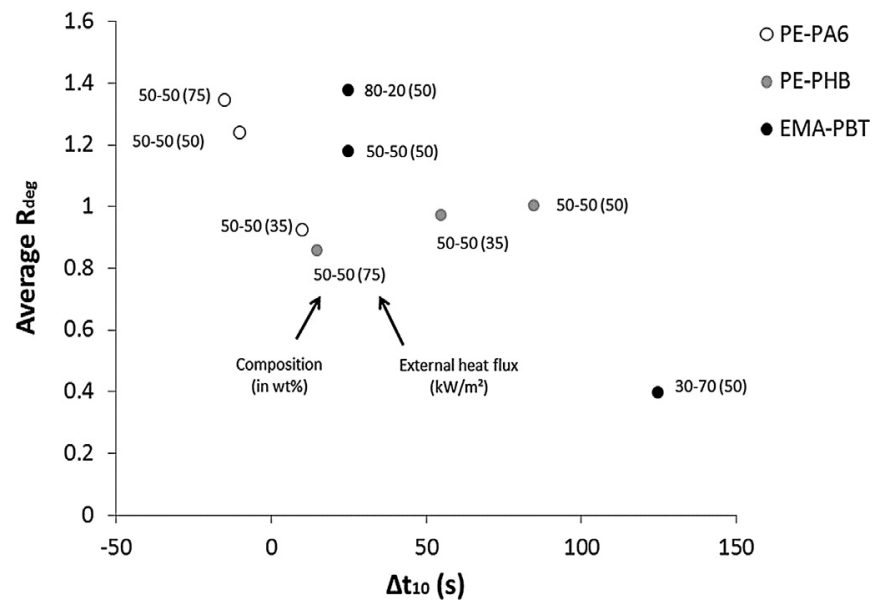

Fig. 20. Average $R_{\text {deg }}$ and $\Delta t_{10}$ for various systems studied.

is degrading so fast that the change in its decomposition rate is almost undetectable above $50 \mathrm{~kW} / \mathrm{m}^{2}$. This explains also why $\Delta \mathrm{t}_{10}$ is relatively low at $75 \mathrm{~kW} / \mathrm{m}^{2}$ (only $15 \mathrm{~s}$ versus $55-85 \mathrm{~s}$ at lower heat fluxes). The comparison between both figures also shows that PHB is degrading much earlier before LDPE at all heat fluxes.

The main objective of this paper is to present the method to distinguish the decomposition rates of two polymers in blend. But in the next section we will attempt to explain the main observations previously noted.

\section{Discussion}

Main results are summarized in Fig. 20 for the three polymer blends studied in this work: EMA/PBT, LDPE/PA6 and LDPE/PHB. Remind that $\Delta t_{10}$ is the difference between the time for the least stable polymer to reach a mass loss of $10 \%$ and the time for the most stable polymer to reach a mass loss of $10 \%$. Average $R_{\text {deg }}$ is the ratio between the mass loss rate of the least stable polymer and the mass loss rate of the most stable polymer between $20 \%$ and $70 \%$ of their mass loss.

In the whole, it can be observed that $\Delta t_{10}$ increases when the difference in thermal stability increases. Its value is close to $0 \mathrm{~s}$ for LDPE-PA6 blends, around $25 \mathrm{~s}$ for EMA-PBT blends (except the specimen tested at $75 \mathrm{~kW} / \mathrm{m}^{2}$ ) and around $50 \mathrm{~s}$ for LDPE-PHB blends. The relatively low value for LDPE-PHB tested at $75 \mathrm{~kW} / \mathrm{m}^{2}$ (15 s) is due to the fact that PHB is degrading very fast at medium to high heat flux. Its decomposition rate does not change anymore while the decomposition rate of LDPE still increases when heat flux increases above $50 \mathrm{~kW} / \mathrm{m}^{2}$.

Very interestingly the figure may reveal a surprising correlation between both parameters. Lower is $\Delta t_{10}$ and higher is average $R_{d e g}$. This correlation can be explained as follows: when the least stable polymer starts degrading, the temperature in the pyrolysis zone is more or less maintained at the pyrolysis temperature of this polymer. The pyrolysis front progresses through the specimen and the thickness of the pyrolysis zone increases according to various parameters as heat flux and thermophysical properties (especially thermal conductivity). Obviously other phenomena occur and make the burning more complex as polymer melting, bubbling and convection of the molten phase. Extensive studies of the heat gradient within a burning specimen have been already carried out using thermocouples [29-30]. As long as the least stable polymer is pyrolyzing, the pyrolysis temperature of the most stable polymer is hardly reached. Nevertheless, heat is built up within the material. Longer is the period before the decomposition of this polymer starts (i.e. higher is $\Delta t_{10}$ ), larger is the fraction of the material already heated at the pyrolysis temperature of the least stable polymer. When the least stable polymer is decomposed, the temperature can increase to allow the most stable polymer to pyrolyze. Then its decomposition rate is very fast. Therefore average $R_{\text {deg }}$ is low.

The difference in thermal stability between LDPE and PHB is so high that LDPE starts degrading a long time after PHB. But LDPE is already at the PHB pyrolysis temperature within the whole specimen whichever applied heat flux. Consequently the mass loss rate of LDPE is higher than the mass loss rate of PHB (and also than LDPE in LDPE-PA6 blends). Average $R_{\text {deg }}$ is always lower than 1 .

On the contrary, when there are few differences in thermal stability between both polymers as in the case of LDPE-PA6 and EMAPBT $80-20$ and $50-50$, average $R_{\text {deg }}$ is higher than 1 : the mass loss rate of the least stable polymer is the highest. One exception is the blend EMA/PBT 30/70. $\Delta \mathrm{t}_{10}$ is very high and EMA starts degrading a long time after PBT. This may be due to the fact that PBT is the matrix in this blend. In that case, the temperature in condensed phase is maintained close to the pyrolysis temperature of PBT up to this polymer is almost fully decomposed.

\section{Conclusion}

A method is proposed to distinguish the relative mass loss rates for a material exhibiting two decomposition steps. One condition to apply this method is that the effective heats of combustion of both steps are known and different enough. This includes many polymer binary blends, but also some copolymers, polymers filled with hydrated fillers and two-layer composites.

Calculated heat release rate curves fit very well experimental curves allowing a new insight on the fire behavior of materials, even if many systems remain too complex as ternary blends, or halogen-containing materials.

Polymer blends exhibit quite often lower peak of heat release rate as expected (according to a linear rule of mixtures), not only because the mass loss rate peaks of both polymers occur at different times, but also because the mass loss rate of one or both polymers is slowed down.

First results show that the least thermally stable component in the material decomposes earlier, but not necessarily faster than the most thermally stable one. Indeed, the temperature in the condensed phase may be mainly controlled by the pyrolysis of the least thermally stable polymer. When the thermal stabilities are very different, the time before the most thermally stable polymer starts to decompose is longer, but this polymer is heated to the pyrolysis temperature of the least stable polymer during this period. When its decomposition starts, its mass loss rate is then very high.

We hope that this method will help to better understand the fire behavior of materials in cone calorimeter tests. The method can also be applied to other fire tests, if mass loss and heat release are measured continuously during the test.

\section{Supplementary materials}

Supplementary material associated with this article can be found, in the online version, at doi:10.1016/j.combustflame.2016.04. 016.

\section{References}

[1] B. Schartel, T.R. Hull, Development of fire-retarded materials - Interpretation of cone calorimeter data, Fire Mater. 31 (2007) 327-354.

[2] B. Schartel, M. Bartholmai, U. Knoll, Some comments on the use of cone calorimeter data, Polym. Degrad. Stab. 88 (2015) 540-547.

[3] R.E. Lyon, J.G. Quintiere, Criteria for piloted ignition of combustible solids, Combust. Flame 151 (2007) 551-559.

[4] D. Hopkins, J. Quintiere, Material fire properties and predictions for thermoplastics, Fire Saf. J. 26 (1996) 241-268. 
[5] B. Rhodes, J. Quintiere, Burning rate and flame heat flux for PMMA in a cone calorimeter, Fire Saf. J. 26 (1996) 221-240.

[6] F. Jiang, J. de Ris, M. Khan, Absorption of thermal energy in PMMA by in-depth radiation, Fire Saf. J. 44 (2009) 106-112.

[7] E. Oztekin, S. Crowley, R. Lyon, S. Stoliarov, P. Patel, R. Hull, Sources of variability in fire test data: a case study on poly(aryl ether ether ketone) (PEEK), Combust. Flame 159 (2012) 1720-1731.

[8] R. Sonnier, A.S. Caro-Bretelle, L. Dumazert, M. Longerey, B. Otazaghine, Influence of radiation-crosslinking on flame retarded polymer materials-How crosslinking disrupts the barrier effect, Radiat. Phys. Chem. 106 (2015) 278-288.

[9] F. Le Lay, J. Gutierrez, Assessment of the mechanical performance of phenolic laminates after ageing in a marine environment, ACMC/SAMPE Conference on Marine Composites Plymouth (2003) ISBN 1-870918-02-9.

[10] S. Feih, Z. Mathys, G. Mathys, A. Gibson, M. Robinson, A. Mouritz, Influence of water content on failure of phenolic composites in fire, Polym. Degrad. Stab. 93 (2008) 376-382.

[11] U. Braun, B. Schartel, Flame retardancy mechanisms of aluminium phosphinate in combination with melamine cyanurate in glass-fibre-reinforced Poly(1,4-butylene terephthalate), Macromol. Mater. Eng. 293 (2008) 206-217.

[12] U. Braun, H. Bahr, H. Sturm, B. Schartel, Flame retardancy mechanisms of metal phosphinates and metal phosphinates in combination with melamine cyanurate in glass-fiber reinforced poly(1,4-butylene terephthalate): the influence of metal cation, Polym. Adv. Technol. 19 (2008) 680-692.

[13] J. Sahyoun, V. Bounor-Legaré, L. Ferry, R. Sonnier, A. Bonhommé, Ph. Cassagnau, Influence of organophosphorous silica precursor on the thermal and fire behaviour of nylon copolymer, Polym. Degrad. Stab. 115 (2015) 117-128.

[14] H. Seefeldt, U. Braun, Burning behavior of wood-plastic composite decking boards in end-use conditions: the effects of geometry, materials composition, and moisture, J. Fire Sci. 30 (2011) 41-54.

[15] R. Kramer, M. Zammarano, G. Linteris, U. Gedde, J. Gilman, Heat release and structure collapse of flexible polyurethane foam, Polym. Degrad. Stab. 95 (2010) 1115-1122.

[16] R.E. Lyon, R.N. Walters, Pyrolysis combustion flow calorimetry, J. Anal. Appl. Pyrolysis 71 (2004) 27-46.

[17] C. Huggett, Estimation of rate of heat release by means of oxygen-consumption measurements, Fire Mater. 4 (1980) 61-65.

[18] P. Hornsby, R. Rothon, Fire retardant fillers for polymers, chapter 2, in: M. Le Bras, C. Wilkie, S. Bourbigot, S. Duquesne, C. Jama (Eds.), Fire Retardancy of Polymers, Royal Society of Chemistry, 2005.
[19] E. Gallo, B. Schartel, D. Acierno, F. Cimino, P. Russo, Tailoring the flame retardant and mechanical performances of natural fiber-reinforced biopolymer by multi-component laminate, Compos.: Part B 44 (2013) 112-119.

[20] Z. Yu, J. Liu, Y. Zhang, J. Luo, C. Lu, B. Pan, Thermo-oxidative degradation behavior and fire performance of high impact polystyrene/magnesium hydroxide/microencapsulated red phosphorus composite with an alternating layered structure, Polym. Degrad. Stab. 115 (2015) 54-62.

[21] A. Viretto, R. Sonnier, A. Taguet, B. Otazaghine, L. Ferry, J.-M. Lopez-Cuesta Thermal degradation of polyesters filled with magnesium dihydroxide and magnesium oxide, Fire Mater. 40 (3) (2016) 445-463.

[22] C. Hoffendahl, G. Fontaine, S. Duquesne, F. Taschner, M. Mezger, S. Bourbigot, The combination of aluminum trihydroxide (ATH) and melamine borate as fire retardant additives for elastomeric ethylene vinyl acetate (EVA), Polym. Degrad. Stab. 115 (2015) 77-88.

[23] J. Zhang, X. Wang, F. Zhang, R. Horrocks, Estimation of heat release rate for polymer-filler composites by cone calorimetry, Polym. Test. 23 (2004) 225-230.

[24] R. Sonnier, B. Otazaghine, L. Ferry, J-M. Lopez-Cuesta, Study of the combustion efficiency of polymers using a pyrolysis-combustion flow calorimeter, Combust. Flame 160 (2013) 2182-2193.

[25] M. Zanetti, G. camino, R. Mülhaupt, Combustion behaviour of EVA/fluorohectorite nanocomposites, Polym. Degrad. Stab. 74 (2011) 413-417.

[26] M. Batistella, B. Otazaghine, R. Sonnier, A.S. Caro-Bretelle, C. Petter J.M. Lopez-Cuesta, Fire retardancy of ethylene vinyl acetate/ultrafine kaolinite composites, Polym. Degrad. Stab. 100 (2014) 54-62.

[27] R. Sonnier, A. Viretto, A. Taguet, J.M. Lopez-Cuesta, Influence of the morphology on the fire behavior of a polycarbonate / poly(butylene terephtalate) blend, J. Appl. Polym. Sci. 125 (2012) 3148-3158.

[28] P. Patel, R. Hull, A. Stec, R. Lyon, Influence of physical properties on polymer flammability in the cone calorimeter, Polym. Adv. Technol. 22 (2011) 1100-1107.

[29] B. Schartel, A. Weib, Temperature inside burning polymer specimens: pyrolysis zone and shielding, Fire Mater. 34 (2010) 217-235.

[30] C. Vovelle, J.L. Delfau, M. Reuillon, J. Bransier, N. Laraqui, Experimental and numerical study of the thermal degradation of PMMA, Combust. Sci. Technol. 53 (1987) 187-201. 